\title{
A reforma educacional do Acre: um modelo híbrido
}

\author{
Ednacelí Abreu Damasceno* \\ Lucíola Licínio de Castro Paixão Santos**
}

Resumo

* Professora do Centro de Educação, Letras e Artes (CELA) da Universidade Federal do Acre (UFAC)

Este artigo analisa as propostas adotadas pelas reformas educacionais no Acre, no período entre 1999 e 2009. Argumenta que essas propostas adquirem um caráter híbrido, em que

** Professora da Faculdade de Educação da Universidade Federal de Minas Gerais (UFMG) se mesclam tanto orientações de natureza mais econômica, afinadas com princípios e práticas do novo gerencialismo, como orientações de natureza mais progressista, coerentes com as teorias críticas e em que a educação é vista como forma de emancipação social. Para isso, são analisadas as políticas de formação, de carreira e de remuneração dos professores da rede estadual, buscando apreender as diferentes lógicas, discursos e ações políticas implementadas, a fim de revelar sua dinâmica social. Conclui-se que, nesse modelo híbrido, os resultados das reformas analisadas mostram-se bastante positivos e sugere-se que um balanço mais completo dessas políticas só poderá ser realizado a longo prazo, a partir de novas investigações, em que a questão da justiça social seja considerada como critério. Observa-se, por fim, que esse tipo de estudo só poderá ser feito em um contexto em que a análise se fundamente não apenas em dados estatísticos, mas em aspectos que levem em conta o processo educacional como um processo de formação humana.

\section{PALAVRAS-ChAVE}

Reforma Educacional. Política educacional. Trabalho docente. Educação no Acre 
INTRODUÇÃO

A literatura na área da educação, nas duas últimas décadas, vem discutindo as repercussões das reformas educacionais na qualidade da educação básica, questão que ganha relevo em um cenário em que a educação passa a ocupar lugar de destaque na agenda política e social de diferentes países. 0 modo como essas políticas de reforma são formuladas e implementadas indica a importância atribuída à área educacional nesse contexto e oferece elementos que podem explicar a razão do sucesso, do fracasso e dos limites das ações governamentais. Para entender esse processo de reformas educacionais, é importante identificar as particularidades, as características e as formas sob as quais elas se configuram em determinados locais e períodos.

0 contexto aqui analisado refere-se ao das reformas educacionais implementadas no estado do Acre de 1999 a 2009. Este trabalho tem como objetivo analisar e discutir as propostas de ação presentes nas reformas educacionais ocorridas no Acre neste período. 0 argumento central é de que nessas reformas mesclaram-se orientações políticas distintas, o que permite classificá-las como reformas de caráter híbrido, ${ }^{1}$ do ponto de vista político.

A primeira parte do artigo se volta para a discussão das reformas e das mudanças educacionais implementadas no Acre durante o período citado, dando destaque ao modelo de gestão proposto nesse processo. Nas duas últimas partes, discutem-se as principais ações, estratégias e metas assumidas pelas reformas, bem como as mudanças relativas às condições de trabalho dos docentes da rede pública estadual acriana. Esse último aspecto tem como referência a política de formação de professores, as mudanças relativas ao plano de carreira e à política salarial docente.

Tanto no cenário nacional, quanto no estado do Acre, as propostas de reformas educacionais emergem nas últimas décadas, envolvendo modificações de várias ordens nos sistemas de ensino. Para Santos (2003), apesar de guardarem concepções e formas de implementação, geralmente, bem diferentes, apresentam alguns aspectos comuns, tais como: autonomia das escolas, gestão participativa, processos de descentralização financeira, reformas curriculares, ênfase na qualidade e na avaliação.

O conceito de hibridismo mostra-se fecundo para expressar uma das idéias centrais deste artigo, como será visto mais adiante. Tem como referência inicial as idéias de Néstor García Canclini (2008) a este respeito. A referência é INICIAL, por se tratar de um conceito que abarca muitos significados, ao mesmo tempo, está sendo deslocado do contexto em que foi utilizado, para ser recontextualizado no interior deste texto. 


\begin{abstract}
Ainda de acordo com Santos (2003), essas propostas, embora possuam esses pontos em comum, fundamentam-se em duas orientações distintas. A primeira dessas orientações apresenta uma concepção mais economicista da educação, enquanto a segunda está voltada para uma concepção progressista e mais coerente com os interesses educacionais mais amplos, não vinculados apenas a demandas do mercado de trabalho. Essas duas orientações diferenciam-se da seguinte forma:
\end{abstract}

\begin{abstract}
A primeira dessas orientações é coerente com os princípios postos pelos organismos internacionais, como o Banco Mundial, cuja preocupação maior é a melhoria da eficiência do sistema educacional, de modo que se possibilite uma educação mais voltada para as demandas do mercado de trabalho, aumentando a competitividade da mão de obra brasileira. Argumenta-se que os investimentos em educação têm sido improdutivos, pelo baixo retorno que apresentam. Além disso, considera-se que as práticas pedagógicas estão desatualizadas, os professores despreparados e que o ensino está desvinculado das exigências colocadas pelas transformações ocorridas no setor produtivo [...].
\end{abstract}

\begin{abstract}
A segunda dessas orientações é compartilhada por grupos de educadores críticos preocupados não só com os aspectos econômicos da educação, mas com sua importância formativa. Para esse grupo, é preciso melhorar o desempenho do sistema não tentando economizar recursos, mas, ao contrário, aumentando-se os investimentos públicos em educação [...]. O objetivo é preparar as pessoas não só para o mercado de trabalho, mas para serem cidadãs, capazes de atuar em todas as esferas da vida pública. (SANTOS, 2003, p. 162-63)
\end{abstract}

No entanto, Santos (2009, p. 14) adverte que esta é uma polarização, feita para fins didáticos, não se apresenta, na realidade, de maneira tão dicotômica. Ela é feita em plano teórico ideal, para servir de guia para a análise, pois quando se examinam os projetos educacionais, sobretudo nos locais em que ocorrem, percebe-se que contêm em seu interior matrizes de ordem filosófica e política bastante distintas, que se chocam e se combinam, sendo quase impossível enquadrá-los em um determinado modelo teórico. Essa mescla de orientações, presentes nos textos das propostas de reformas, bem como no seu processo de implementação, decorrentes da apropriação pelos sujeitos dos diferentes discursos e práticas que circulam no contexto onde atuam, pode ser considerada como decorrentes de um processo de hibridização. ${ }^{2}$

\footnotetext{
Néstor Garcia Canclini (2008) empregou a expressão culturas híbridas para discutir a modernidade latinoamericana. 0 autor critica a posição que assume não se poder falar em pós-modernidade na América Latina, uma vez que o projeto da modernidade ainda estaria incompleto nessa região. Canclini se opõe a uma visão etapista do desenvolvimento sócio-cultural latinoamericano e defende a ideia de que o que caracteriza a América Latina é essa mescla de culturas, provenientes de locais e tempos diferentes.
} 
O hibridismo se configura como uma categoria analítica que pode aqui ajudar a compreender como as políticas educativas são criadas e implementadas no sentido de promover as mudanças desejadas em determinadas realidades sociais. Ao discutir o conceito de "hibridismo" como possibilidade de interpretação não verticalizada dos processos de reformas educacionais, parte-se do entendimento de García Canclini (2008, p. XIX) ao definir "hibridação" como "processos socioculturais nos quais estruturas ou práticas discretas, que existiam de forma separada, se combinam para gerar novas estruturas, objetos e práticas".

A afirmação do caráter híbrido das reformas educacionais no Acre tem um duplo sentido. Por um lado, os sujeitos envolvidos nessas reformas possuem culturas, tradições, práticas e concepções próprias, podendo-se dizer que, em cada realidade local em que as reformas são implementadas, terminam por ser recontextualizadas em um processo de mesclagem com tradições locais. Por outro lado, os processos de hibridação estão presentes no interior das próprias reformas, ao combinarem diferentes concepções e orientações teóricas, no conjunto das ações planejadas e desenvolvidas.

Em muitos casos, de acordo com García Canclini (2008), essa relação nem sempre é só de enriquecimento, ou de apropriação pacífica, mas também conflitiva. Dessa forma, é possível reconhecer nos hibridismos

O que contêm de desgarre e o que não chega a fundir-se. Uma teoria não ingênua da hibridação é inseparável de uma consciência crítica de seus limites, do que não se deixa, ou não quer ou não pode ser hibridado. (GARCÍA CANCLINI, 2008, p. XXVII)

A incorporação da idéia dos processos de hibridação permite uma melhor e mais cuidadosa análise das propostas das reformas implementadas no Acre, revelando melhor a dinâmica social dos movimentos ocorridos nas redes de ensino públicas. 0 conceito de hibridismo possibilita que se entenda a política educacional, evitando classificações ou rotulações enviesadas por apenas focalizarem uma dimensão de um processo que é multifacetado.

Assim, por exemplo, pode-se entender por que as políticas referentes à gestão escolar foram marcadas pela convivência de práticas filiadas a diferentes orientações políticas. Ao mesmo tempo em que foi institucionalizada a eleição de diretores pela comunidade escolar, garantindo não só a autonomia para as unidades de ensino elaborarem e implementarem seus projetos pedagógicos, políticos e administrativos, como também uma gestão participativa com a presença de todos os segmentos dos sujeitos da escola em suas instâncias decisórias (Cf. Lei 1.513/2003), passou-se a exigir dos 
professores que almejam candidatar-se ao cargo de diretor a realização de curso de capacitação para gestores com exame final de certificação. ${ }^{3}$ Desse modo, uma concepção democrática de gestão, defendida pelos educadores críticos se combina com uma visão mais gerencialista da educação expressa na defesa do exame de certificação. ${ }^{4}$

Outro exemplo pode ser apontado quando se observa que algumas medidas caminham para desenvolver nas escolas uma cultura de trabalho coletivo e participativo e uma prática de gestão mais autônoma, utilizando-se como instrumento, a elaboração do Projeto Político-Pedagógico (PPP). Contudo, ao mesmo tempo, ao firmar convênios com o Banco Mundial, a Secretaria Estadual de Educação do Acre também definiu como necessidade, para uma gestão mais moderna e eficiente, a elaboração do Plano de Desenvolvimento da Escola (PDE-Escola), que segue um modelo de planejamento estratégico apoiado na racionalização e na eficiência administrativa.

Segundo Fonseca (2003), o PPP e o PDE-Escola são duas concepções antagônicas de gestão educacional, provenientes de diferentes matrizes teóricas. O primeiro sinaliza para uma comunidade escolar mais autônoma, enquanto o segundo, de caráter gerencial, descarta a base política do primeiro e fortalece o viés tecnicista. Tal situação tem gerado, atualmente, nas escolas, dificuldades no desenvolvimento dos dois modelos de planejamento educacional, o que ocasiona, de certa forma, o fortalecimento do PDE-Escola em detrimento do PPP.

As condições de trabalho docente são outro aspecto que pode ser analisado sob a argumentação de que, no movimento de reformas educacionais do Acre, há diferentes lógicas que convivem na produção de políticas e práticas, interrelacionando-se ou não. Por um lado, percebe-se uma orientação coerente com propostas defendidas pelas diversas organizações e associações de professores, como melhorias salariais, progressão na carreira, formação em nível superior para todos os docentes da rede pública, escolas reformadas, etc. Por outro lado, adotam-se discursos e propostas em que está presente

A certificação faz parte da modalidade de escolha dos diretores das escolas da rede estadual, constituindo-se na primeira etapa do processo classificatório. Só poderá concorrer ao cargo de diretor o candidato que tiver obtido o mínimo de setenta por cento de aproveitamento nessa fase.

4 Os exames de certificação têm sido uma política adotada pelos países e estados que se alinham com as propostas das organizações multilaterais (Organização para Cooperação e Desenvolvimento Econômico - OCDE; Bancos Multilaterais de Desenvolvimento - BMD, como o Banco Mundial - BM e outras agências). Merece destaque a ação dos Bancos Multilaterais que, geralmente, preconizam para o setor público políticas e ações utilizadas no setor privado, com o objetivo de tornar o primeiro tão produtivo como o segundo, sem uma análise da diferença das finalidades e dos serviços prestados por esss dois setores. 
a defesa da ideia de que a qualidade na educação depende basicamente do desempenho dos professores e da equipe de gestão da escola, ausentandose desses discursos outros fatores importantes, relativos à infra-estrutura da escola, às condições de trabalho, ao salário e, acima de tudo, às condições de vida população que frequenta a escola pública, fatores que se relacionam diretamente ao rendimento escolar.

Esses aspectos evidenciam o caráter híbrido do conjunto de políticas educacionais que, ao longo do período aqui analisado, foram implementadas, associando propostas alinhadas a um projeto mais progressista, defendido pelos educadores críticos, a propostas de caráter gerencialistas, sintonizadas a uma visão mais economicista da educação. Essas duas abordagens se assentam em diferentes perspectivas sobre a educação, a escola e os professores.

O exercício de identificar posições e orientações diferentes nas reformas educacionais do Acre foi um trabalho para mostrar seu caráter híbrido, anunciando-se assim a impossibilidade de classificá-las dentro dos padrões muitas vezes utilizados pela literatura educacional (de esquerda, progressista, neoliberal, etc.). Isso não as isenta de serem avaliadas no seu conjunto em termos de justiça social, como defende Ball (1994), identificando se seus resultados revelam conquistas nesse aspecto.

\section{Reformas e MudançAs Educacionais}

Em 1999, tem início uma nova gestão de governo, estando à frente do executivo estadual Jorge Viana, eleito pelo Partido dos Trabalhadores (PT) em uma coligação partidária denominada Frente Popular do Acre. Engenheiro florestal, Jorge Viana governou, então, o Estado por dois mandatos (19992002/2003-2006), sob uma gestão autodenominada “Governo da Floresta”. Foi sucedido, em 2007, pelo professor Arnóbio Marques de Almeida Júnior (Binho Marques), apoiado por Jorge Viana e em cujos mandatos assumira a Secretaria de Estado da Educação. Esse grupo político se mantém no poder executivo até os dias de hoje com o atual governador Tião Viana, ex-senador da República e irmão do antigo governador do estado Jorge Viana. No entanto, ainda é cedo para avaliar se o atual projeto de governo, principalmente no que tange às ações voltadas para a educação, mantém ou não a continuidade e a consistência das reformas e políticas implementadas na década anterior, pelos três governos que o antecederam. ${ }^{5}$

Para efeito deste artigo, a análise sobre o processo de reforma educacional concentrarse-á em alguns elementos importantes que darão uma moldura interpretativa das políticas educacionais implementadas no decorrer do período de 1999 a 2009. 
No primeiro mandato de Jorge Viana (1999-2002), seu programa de governo, sob o SLOGAN "A vida vai melhorar", trazia grandes expectativas de melhorias na condição de vida dos acrianos. A proposta de governo incluía a adoção de políticas públicas voltadas tanto para a elevação dos níveis sociais de vida e renda da população acriana, quanto para a proteção e desenvolvimento do meio ambiente. Tal programa tinha como um de seus elementos centrais a implantação de um novo modelo de desenvolvimento econômico, fomentado pela exploração racional dos recursos regionais, como por exemplo, o manejo florestal.

A primeira medida adotada pela Frente Popular do Acre voltou-se claramente para uma ampla reforma do Estado 6 que, segundo os documentos legais, visava assegurar a viabilidade técnica do desenvolvimento sustentável e garantir a funcionalidade do aparelho estatal, priorizando as atribuições de cada setor e reorganizando as secretarias. ${ }^{7}$

Basicamente, a estrutura da administração pública estadual foi organizada em três grandes áreas, com suas respectivas secretarias de governo:

A. ÁREA DA GESTÃo - composta pela Secretaria de Estado do Planejamento e Coordenação; Secretaria de Estado da Fazenda; Secretaria de Estado da Administração e Recursos Humanos.

B. Área do Desenvolvimento Humano - composta pela Secretaria de Estado de Educação; Secretaria de Estado da Saúde e Saneamento; Secretaria de Estado de Justiça e Segurança Pública; Secretaria de Estado de Cidadania, do Trabalho e Assistência Social.

C. Área do DESENVOLVIMENTO ECONÔMICO-SUSTENTÁVEL - composta pelas secretarias de Estado de Infra-estrutura, de Produção, de Ciências, Tecnologia e Meio Ambiente.

Nas gestões dos governos anteriores à administração do PT, a máquina burocrática do Estado pouco sofreu alterações. Na gestão iniciada em 1999, o Governo optou por realizar uma ampla reforma, não só do aparelho do Estado, mas na própria concepção de gestão, estabelecendo novas relações com o funcionalismo público. A formação e a capacitação de todos os funcionários lotados nos setores administrativos e a modernização da infra-estrutura dos órgãos de governo foram medidas tomadas no processo de reestruturação do aparelho de gestão do Estado.

Lei Complementar № 63, de 13 de janeiro de 1999.

Lei Complementar № 72, de 05 de julho de 1999. 
Dentre as ações de maior destaque, no conjunto das mudanças ocorridas no período, encontra-se o amplo processo de reformas educacionais. Segundo documentos oficiais, a primeira proposta de reformas foi materializada pelas metas do Planejamento Estratégico Situacional (PES), elaborado, a partir de um diagnóstico institucional amplo em que, segundo o ex-Secretário de Educação, Arnóbio Marques de Almeida Júnior (2006), duas ações do ponto de vista da capacidade institucional foram consideradas centrais para a implementação de uma nova gestão. ${ }^{8}$ Uma dessas ações deveria combater, na perspectiva do governo, um "sistema gerencial deficiente”, caracterizado pela má utilização dos recursos destinados à educação e pela cultura institucional da própria Secretaria de Educação, que não cobrava resultados e não avaliava as ações dos profissionais ocupantes de cargos/funções de gestão.

A outra ação considerada central na implementação do processo de reforma educacional consistiu em estabelecer uma mudança radical na relação entre o governo e o sindicato dos professores. Este, por seu "corporativismo predominante", foi reconhecido pelo próprio governo como uma ameaça aos projetos de reforma.

Essa relação entre governo e sindicato obedecia, segundo Almeida Júnior (2006), ao seguinte ciclo: iniciava-se com o movimento de greve liderado pelo sindicato dos professores para pressionar o governo por percentuais de aumento; o governo, por sua vez, fazia uma contraproposta ao sindicato, justificada pela falta de dinheiro; terminava com a categoria aceitando o percentual "possível” no processo de negociação, retornando às atividades e já se preparando para uma nova mobilização.

Para quebrar essa rotina, segundo o próprio Secretário de Educação, foi necessário contrapor-se ao discurso sindicalista, evidenciando que nem todos os professores tinham salários tão baixos quanto os divulgados nos movimentos de greve. A análise do governo, na época, evidenciou que:

Utiliza-se aqui a dissertação de mestrado de Binho Marques. Expressa-se, assim, por meio de seu trabalho, o ponto de vista de um dos agentes envolvidos nas reformas. Como já se indicou, Arnóbio Marques de Almeida Júnior foi Governador do Acre entre 20072011. Além disso, foi Secretário de Educação (1999-2006) durante os dois mandatos de Jorge Viana. No segundo mandato deste, acumulou o cargo de vice-governador e a direção das secretarias de Educação e de Desenvolvimento Humano e Inclusão Social (2003-2006). Durante a gestão de Jorge Viana à frente da prefeitura de Rio Branco, foi Secretário de Educação do Município (1993-1996). 
Olhando para o Plano de Carreira, os salários eram baixos, mas o gasto com a folha era muito alto. A resposta era muito simples e óbvia como parecia. Uma análise do plano de carreira demonstrou que: (1) os "salários de miséria" (como eram chamados nas assembléias) eram de $80 \%$ dos professores, mas 20\% dos professores recebiam bons salários; (2) praticamente ninguém recebia os piores salários do Plano, pois a grande maioria dos trabalhadores estava concentrada no meio da carreira; (3) nenhum professor recebia apenas o salário, já que todos tinham acesso a um conjunto de gratificações que tornava a remuneração final quase o dobro do salário nominal do Plano de Careira; (4) ninguém trabalhava 40 horas semanais, já que seus contratos haviam sido alterados de 20 para 40 horas semanais no início dos anos 80, a título de hora-atividade, apenas para o governo justificar um aumento só para os professores; (5) muitos professores tinham excelentes salários, já que tinham incorporado definitivamente a seus rendimentos a remuneração de cargos que ocuparam na administração pública, através de um artifício legal (ALMEIDA JÚNIOR, 2006, p. 73).

Almeida Júnior (2006) afirma que o ritual desse ciclo era compactuado pela maioria das lideranças sindicais e pelos dirigentes da Secretaria de Educação, e explica que tal situação era mantida em razão do seguinte arranjo:

Da parte do sindicato, a maioria das lideranças estava na condição dos $20 \%$

mais bem remunerados. A presença dos baixos salários ajudava na mobilização

e na manutenção de um grupo salarial em menor número com vencimentos

muito acima da média. Uma tabela salarial mais equitativa, ou seja, mais curta, com vencimentos sem discrepância entre o piso e o teto salarial inviabilizaria a manutenção de privilégios. Da parte do Governo, pouco interessava a equidade da carreira. Os dirigentes da Secretaria de Educação também faziam parte do grupo dos 20\%. Por outro lado, questionar profundamente o contracheque (holerite) dos sindicalistas poderia provocar, como reação, questionamento sobre o volume e destino dos recursos da educação e de uma camada mais privilegiada - os “apadrinhados" do poder, aqueles que recebiam sem trabalhar (ALMEIDA JÚNIOR, 2006, p. 74).

Com essa questão descortinada, segundo Almeida Júnior (2006, p. 75), o governo "iniciou um processo de alteração (ainda em curso) de uma relação de 'chantagem' para a relação de respeito profissional entre professores e secretaria" e "no lugar de administrar ou manter a situação, concedendo apenas um aumento linear, resolveu desenvolver, ou mudar, a política salarial, partindo para a criação de um novo plano de carreira” (p.75).

A mudança na forma de o governo se relacionar com o sindicato e a nova política salarial foram consideradas, por Almeida Júnior (2006), atitudes indispensáveis para alterar o contexto institucional, contribuindo, assim, para empreender e consolidar um estilo de governança com controle e negociação. 
Foram, então, criadas as condições necessárias para que o projeto político do governador Jorge Viana, em seus dois mandatos e no de seu sucessor, o próprio, Arnóbio Marques Almeida Júnior, fosse, de fato, implementado, firmando-se um tripé assim identificado: projeto, capacidade de governo e governabilidade.

A mobilização dos sujeitos envolvidos nos processos de reforma também foi uma das ações utilizadas para adequar as demandas aos interesses estratégicos da política governamental, por meio do gerenciamento racional dos recursos disponíveis e da redefinição de papéis, tanto dos gestores da Secretaria de Educação, quanto da comunidade escolar.

A existência do PES permitiu a realização de um pacto com a comunidade escolar e com os gestores da secretaria. Isto foi suficiente para amenizar a tensão que cerca qualquer decisão sobre os investimentos. O Plano permitiu que todos tivessem clareza das prioridades e se sentissem, ao mesmo tempo, autores e cúmplices delas. Os objetivos estratégicos bem definidos e articulados com a missão aumentaram a eficiência e a eficácia da secretaria (ALMEIDA JÚNIOR, 2006, p. 115).

O setor educacional assumiu o discurso da modernização educativa, da gerência, da descentralização, da autonomia escolar, da produtividade, da eficiência e da qualidade do ensino, na busca da superação dos resultados insatisfatórios até então obtidos pela rede estadual nas avaliações nacionais.

No setor, as políticas públicas centralizaram-se nos primeiros quatro anos do governo Jorge Viana, conforme o Plano Estratégico, em quatro objetivos específicos: a) garantir qualidade na educação básica; b) assegurar condições mínimas de funcionamento das escolas; c) modernizar a gestão educacional e d) democratizar o acesso ao ensino público e gratuito e a permanência na escola.

Em relação ao objetivo que se refere às “condições mínimas de funcionamento das escolas", o processo iniciou-se com reformas em todas as unidades escolares do meio urbano, adequando a grande maioria ao novo projeto arquitetônico que levou em consideração três aspectos: o ambiente, a cultura e o projeto pedagógico. Alguns modelos arquitetônicos foram definidos e implementados. Os modelos variavam segundo a localização, etapa e a modalidade de ensino oferecida pela escola: urbana infantil ou de ensino fundamental (anos iniciais); rural de uma ou duas salas; rural com quatro salas ou mais; indígena; urbana de ensino fundamental (anos finais); e urbana de ensino médio. No meio rural, $40 \%$ das escolas foram reconstruídas, perfazendo um total de 232 escolas. ${ }^{9} \mathrm{Um}$

É importante observar alguns dados sobre o Acre. O Censo Demográfico de 2010 contabilizou 733.559 habitantes no Estado, com população em idade escolar de 233.761 crianças e jovens. Frequentam a rede pública de ensino: 21.401 alunos da educação infantil; 155.894 alunos no ensino fundamental; 33.975 alunos no ensino médio e 
terço das escolas indígenas também foi reconstruído, a partir de um modelo culturalmente adequado para essa modalidade. Na Capital e na zona urbana dos principais municípios, também se deu um amplo processo de ampliação, reconstrução e construção de escolas. Ao lado disso, foi planejado e produzido um mobiliário adequado a cada uma dessas tipologias escolares, sendo então instalado nas unidades.

Em relação ao objetivo que se refere à “modernização da gestão educacional”, o modelo implementado subordinou todas as ações ao desempenho dos alunos, num sistema de avaliação fortemente caracterizado pela preocupação com os resultados. O ETHOS cultural, tanto da secretaria quanto da escola, passa a ser influenciado pelos princípios defendidos pela nova lógica de administração pública adotada. Esse modelo de gestão tem no Planejamento Estratégico um aliado da governabilidade, e se fundamenta na descentralização e na flexibilidade. A preocupação em manter uma cultura unificada em todo o sistema de ensino, subordinando-a aos propósitos das reformas educacionais, modificou todo o desenho organizacional da secretaria vigente nos períodos governamentais anteriores.

Para garantir os resultados de eficácia e eficiência do ensino, a Secretaria de Educação estruturou-se a partir de um conceito de gestão denominado “Triângulo do Governo", composto por três vértices: o programa de governo, a capacidade do governo e a governabilidade do sistema. De acordo com Belchior (1999), esses três vértices condicionam-se mutuamente e devem ser equacionados simultaneamente. O "programa de governo" diz respeito às propostas que o planejador, no caso, o governo, tem em mente com base nos seus objetivos. A “capacidade de governo" é sua competência na condução dos processos, referindo-se às técnicas, métodos, destrezas, habilidades e experiências do gestor e de sua equipe para conduzir o projeto de governo à consecução dos objetivos declarados (MATUS, 1993). A "governabilidade do sistema" compreende as variáveis que farão parte do processo de planejamento e que, por sua vez, podem ser divididas em: controladas "pelo gestor do planejamento" e não-controladas.

Almeida Júnior (2006) foi quem esteve à frente desse processo de reformas educacionais consubstanciado no PES. Sua explicação sobre a configuração

22.738 alunos na educação de jovens e adultos (INEP, 2010). Atualmente, de acordo com o Censo Escolar de 2010, a rede pública estadual compreende 671 unidades escolares, sendo 180 urbanas e 481 rurais. 
triangular que adotou para a nova estrutura organizacional da Secretaria resume-se no seguinte:

O projeto, a finalidade da Secretaria, é o ensino. A secretaria adjunta responsável pela qualidade efetiva do projeto ficou denominada Secretaria Adjunta de Ensino.

Ela unifica e subordina todos os setores e procedimentos relativos ao processo de construção curricular e acompanhamento pedagógico das escolas. Dando suporte ao projeto da Secretaria, as duas outras secretarias adjuntas: Secretaria Adjunta de Recursos, responsável pela gerência de pessoal, compras e infra-estrutura, reduzindo os atritos entre áreas meio e fins, porque subordinada aos resultados do projeto; e a Secretaria Adjunta de Gestão, responsável pela governabilidade do projeto, comandando a relação com as escolas e estabelecendo uma interlocução privilegiada dos diretores com o órgão central. [...].

Esta concepção triangular (mas não piramidal) deve sintetizar também uma espécie de código genético do Sistema de Educação do Acre. Ou seja, toda e qualquer instância da rede de ensino - desde a sede da SEE à menor e mais longínqua escola do Estado - tem que ser e estar estruturada a partir destes três aspectos, seja uma escola periférica do bairro Sobral, em Rio Branco, ou numa escola rural no Alto Purus ou Alto Juruá. Esta estrutura genética tem que estar presente (ALMEIDA JÚNIOR, 2006, p. 89-90, grifo nosso).

Essa estrutura organizacional da Secretaria Estadual de Educação veio a sofrer algumas alterações em 2008, quando a gestão petista já se encontrava em seu terceiro mandato, estando à frente do executivo nesse período o Secretário de Educação das duas gestões anteriores, Arnóbio Marques. Nesse processo, toda a estrutura administrativa do Poder Executivo do Estado foi reformulada, conforme a Lei Complementar $\mathrm{n}$ ํ 191, de 31 de dezembro de 2008. Atualmente, a partir dessa Lei, a estrutura da Secretaria de Educação é hierarquicamente composta por: a) Secretaria Adjunta; b) Diretorias; c) Departamentos e d) Divisões.

A Secretária Adjunta tem a função de Vice-Secretária de Estado de Educação. As Diretorias se organizam em três grandes áreas administrativas: Ensino, Gestão Institucional e Recursos. Uma novidade dessa nova estrutura é a criação da “Divisão de Monitoramento e Avaliação Escolar”, subordinada à Diretoria de Gestão Institucional.

Essas mudanças ocorridas a partir da Lei Complementar no 191/2008 não alteraram a concepção triangular da estrutura de gestão da Secretaria. De certa forma, as antigas "secretarias adjuntas" passaram a ser denominadas de “diretorias”, sendo estas repartidas em “divisões”.

O Secretário de Educação, juntamente com os Diretores de Gestão Institucional, de Ensino e de Recursos, formam o grupo gestor, responsável 
pela definição das grandes linhas norteadoras das ações e programas educacionais do projeto de governo. Segundo documentos oficiais, esse desenho organizacional e institucional, no novo modelo de gestão, ajustou seu formato a uma proposta de monitoramento da gestão das escolas, de modo que essa passasse a ser mais descentralizada, mais participativa e mais comprometida com os resultados.

Diante do exposto, nos processos de reformas educacionais levados a cabo pelo governo do Acre, pode-se observar a presença de alguns elementos que se identificam com as reformas de cunho mais economicista. Nelas, o controle é elemento primordial nos processos de gestão, enquanto as propostas mais progressistas têm como núcleo central a autonomia da escola e dos docentes e o compromisso com os interesses das camadas populares. Esse controle se evidencia na reforma administrativa que mudou a estrutura da secretaria e estabeleceu objetivos estratégicos e planos de ação que foram administrados por líderes e gerentes de metas. Todo o processo foi e continua sendo monitorado e avaliado pelos gestores da Secretaria de Educação. Da mesma forma, esse controle pode ser observado no estabelecimento de uma nova relação com as escolas, que passou a se basear fundamentalmente na exigência de um maior comprometimento dessas instituições com os resultados dos alunos nos testes realizados pelo Sistema Nacional de Avaliação.

Outras políticas educacionais, descritas a seguir, são exemplos de políticas mais afinadas com um ideário mais progressista, defendido pelos educadores críticos. Destacam-se entre elas o aumento de salários, com a implantação de um novo piso e a reformulação do plano de carreira, que trouxe benefícios aos trabalhadores em educação, como, por exemplo, a transformação de todas as gratificações e abonos em salários reais; a construção e a reforma das escolas e o aumento considerável de gastos públicos na área educacional. Todas elas são exemplos de ações políticas mais coerentes com outra concepção de reforma educacional, a que está próxima daquela defendida pelos chamados educadores progressistas, que reivindicam maiores investimentos na educação pública e no desenvolvimento profissional dos professores. De forma diferente, os programas de formação em nível superior dos docentes da rede estadual combinam em seu interior as duas posições, como será visto mais adiante.

A POLÍTICA DE CARREIRA E REMUNERAÇÃO DOS PROFESSORES

A política de carreira e remuneração dos professores da rede estadual é 
concretizada pelo Plano de Cargos, Carreira e Remuneração dos Profissionais do Ensino Público Estadual (PCCR), que foi instituído pela Lei completar no $67 / 1999$. Antes do processo de reforma educacional, a carreira do magistério tinha quinze níveis de progressão automática por tempo de serviço e oito classes por titulação, ilustrados na Tabela 1:

TABELA 1 - Carreira do Magistério do Estado do Acre e Piso Salarial em 1999 (antes da reformulação) ${ }^{10}$

\begin{tabular}{|c|c|c|c|c|c|c|c|c|c|}
\hline $\begin{array}{l}\text { Classe1/ } \\
\text { Letra }\end{array}$ & PE 1 & PE 2 & PE 3 & PE 4 & PE 5 & PE 6 & PE 7 & PE 8 & $\begin{array}{c}\text { Tempo de } \\
\text { Serviço }\end{array}$ \\
\hline $01-A$ & 126,43 & 140,42 & 154,41 & 168,57 & 224,71 & 280,84 & 337,15 & 393,28 & $00-02$ \\
\hline $02-B$ & 132,75 & 147,44 & 162,13 & 177,00 & 235,94 & 294,88 & 354,00 & 412,94 & $02-04$ \\
\hline $03-C$ & 139,39 & 154,81 & 170,24 & 185,85 & 247,74 & 309,63 & 371,70 & 433,59 & $04-06$ \\
\hline $04-D$ & 146,36 & 162,55 & 178,75 & 195,14 & 260,13 & 325,11 & 390,29 & 455,27 & $06-08$ \\
\hline $05-E$ & 153,68 & 170,68 & 187,69 & 204,90 & 273,13 & 341,37 & 409,80 & 478,03 & $08-10$ \\
\hline $06-F$ & 161,36 & 179,22 & 197,07 & 215,15 & 286,79 & 358,43 & 430,29 & 501,94 & $10-12$ \\
\hline $07-G$ & 169,43 & 188,18 & 206,93 & 225,90 & 301,13 & 376,35 & 451,81 & 527,03 & $12-14$ \\
\hline $08-\mathrm{H}$ & 177,90 & 197,59 & 217,27 & 237,20 & 316,19 & 395,17 & 474,40 & 553,38 & $14-16$ \\
\hline $09-1$ & 186,79 & 207,47 & 228,14 & 249,06 & 331,99 & 414,93 & 498,12 & 581,05 & $16-18$ \\
\hline $10-J$ & 196,13 & 217,84 & 239,54 & 261,51 & 348,59 & 435,68 & 523,02 & 610,11 & $18-20$ \\
\hline $11-\mathrm{L}$ & 205,94 & 228,73 & 251,52 & 274,59 & 366,02 & 457,46 & 549,17 & 640,61 & $20-22$ \\
\hline $12-M$ & 216,24 & 240,17 & 264,10 & 288,32 & 384,33 & 480,33 & 576,63 & 672,64 & $22-24$ \\
\hline $13-N$ & 227,05 & 252,18 & 277,30 & 302,73 & 403,54 & 540,35 & 605,46 & 706,27 & $24-26$ \\
\hline $14-0$ & 238,40 & 264,78 & 291,17 & 317,87 & 423,72 & 526,57 & 635,74 & 741,59 & $26-28$ \\
\hline $15-P$ & 250,32 & 278,02 & 305,73 & 333,76 & 444,90 & 556,05 & 667,52 & 778,67 & $28-30$ \\
\hline
\end{tabular}

Fonte: Acre (2002)

Percebe-se, pela distribuição das classes e seus respectivos salários, que a principal dificuldade nos momentos de negociação salarial entre sindicato e governo, como já foi dito, consistia no aumento linear para todos os

10 As classes de titulação estavam assim organizadas: Classe PE 1 - professor com formação específica de $2^{\circ}$ grau com duração de três anos; Classe PE 2 - professor com formação

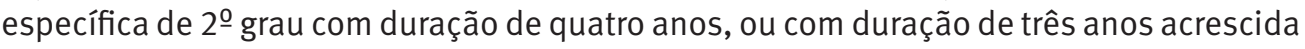
de mais um ano de estudos adicionais; Classe PE 3 - professor com formação de 30 grau, licenciatura curta, na área de educação; Classe PE 4 - professor com formação de 3ำ grau, licenciatura curta, acrescida de um ano de estudos adicionais na área de educação; Classe PE 5 - professor com formação de 3ํ grau, licenciatura plena na área de educação; Classe PE 6 - professor com formação de 3 ํ grau e pós- graduação, nível de especialização, na área de educação; Classe PE 7 - professor com formação de 30 grau e pós-graduação, nível de mestrado, na área de educação; e Classe PE 8 - professor com formação de 3oㅡ grau, nível de doutorado, na área de educação. 
professores, visto que o índice de reposição salarial significaria muito para poucos profissionais, situados nas últimas classes, representadas por $20 \%$ do quadro de servidores, sendo, ao mesmo tempo, insignificante para cerca de $80 \%$ dos servidores, distribuídos pelas primeiras classes do Plano.

O novo Plano de Cargos, Carreira e Remuneração dos Profissionais do Ensino Público Estadual inclui apenas três categorias de professores (P 1 - professor com formação de nível médio na modalidade normal; P 2 - professor com formação em área própria, de nível superior, em curso de licenciatura, de graduação plena, ou formação superior em área correspondente com complementação legal; e P 3 - professor com formação em nível de pósgraduação LATO SENSU, e mestrado ou doutorado, na área de educação). A linha de promoção da carreira dos professores ficou constituída de seis classes designadas pelas letras $A, B, C, D, E$ e $F$, onde os professores foram distribuídos, conforme o tempo de serviço, sendo enquadrados nas letras da carreira a cada sete anos. Ou seja, o docente que tinha até sete anos de carreira foi enquadrado na letra $A$; aquele que tinha entre sete e 14 anos, na letra B e assim sucessivamente. A passagem do profissional da educação de uma classe para outra imediatamente superior é um direito de todos os integrantes da carreira que tenham cumprido o interstício de três anos de efetivo exercício na função e que tenham atingido o mínimo de 70 pontos somados entre a avaliação anual de desempenho (20 pontos), aferição de qualificação $^{11}$ (30 pontos) e a avaliação de conhecimentos da área em que o profissional exerça sua função (20 pontos). O restante da pontuação (30 pontos) corresponde ao tempo de efetivo exercício no cargo, sendo 10 pontos para cada ano. Aos vencimentos foram incorporadas todas as vantagens, bônus e gratificações existentes na época, tornando-se salário. Essa configuração está representada pela Tabela 2.

TABELA 2 - Carreira do Magistério do Estado do Acre e Piso Salarial em 1999 (depois da reformulação)

\begin{tabular}{llllll}
\hline & A & B & C & D & E \\
\hline P1 & 450,00 & 495,00 & 540,00 & 585,00 & 630,00 \\
\hline P2 & 675,00 & 742,00 & 810,00 & 877,50 & 945,00 \\
\hline P3 & 742,50 & 816,75 & 891,00 & 965,25 & $1,039,50$ \\
\hline
\end{tabular}

Fonte: Secretaria de Estado de Educação, PCCR (1999).

${ }_{11}$ No caso da Secretaria de Educação não ofertar os cursos necessários para a qualificação dos profissionais do ensino, os pontos referentes a esse critério de promoção serão creditados automaticamente. 
Em 2001, esses níveis foram reduzidos para dois: P 1 e P 2. Manteve-se a mesma remuneração para os professores com formação de nível médio na modalidade normal ( $P$ 1), alterando a remuneração dos professores com formação nível superior (P 2), ${ }^{12}$ conforme expressos na Tabela3:

TABELA 3 - Carreira do Magistério do Estado do Acre e Piso Salarial em 2001

\begin{tabular}{lllllll} 
& A & B & C & D & E & F \\
\hline P 1 & 450,00 & 495,00 & 540,00 & 585,00 & 630,00 & 675,00 \\
\hline P 2 & $1.200,00$ & $1.320,00$ & $1.440,00$ & $1.560,00$ & $1.680,00$ & $1.800,00$ \\
\hline
\end{tabular}

Fonte: Secretaria de Estado de Educação, PCCR (2001).

Atualmente, o Plano de Cargos, Carreira e Remuneração dos Profissionais do Ensino Público Estadual do Acre, após sofrer várias alterações por Leis Complementares ${ }^{13}$ compõem-se de dez classes para o professor com formação em licenciatura plena e nove para os professores com formação de nível médio (Curso Normal), com jornada contratual de trinta horas e promoção a cada três anos.

Os professores com formação de nível médio em magistério (Professor P1) ingressam na carreira com salário inicial de $R \$ 707,00$ (setecentos e sete reais) para uma jornada de 30 horas semanais. Os professores com formação superior ingressam na carreira do magistério acriano com salário inicial de $\mathrm{R} \$$ $1.675,79$ para uma jornada de trinta horas de trabalho semanal, independente da etapa da educação básica em que atuam. 0 professor da educação infantil ou anos iniciais do ensino fundamental, ao ingressar na carreira, terá o mesmo vencimento que os professores das demais etapas de ensino.

É inegável a existência de uma política de valorização salarial, ao longo desse período, em relação aos profissionais efetivos do ensino público estadual, principalmente se realizada uma análise comparativa com as gestões de governos anteriores. Em 1998, antes da reforma educacional e da aprovação do atual Plano, o salário inicial do professor com formação em licenciatura plena era de $R \$ 224,71$ (Tabela 10 - Classe PE 5), o equivalente em maio de 1999 a 1,6 salário mínimo, ${ }^{14}$ enquanto que, pelo vencimento atual, o salário

12 A Lei Complementar $n$ ㅇ 110, de 28 de junho de 2004 criou um adicional para os professores com licenciatura plena com especialização lato sensu, mestrado e doutorado.

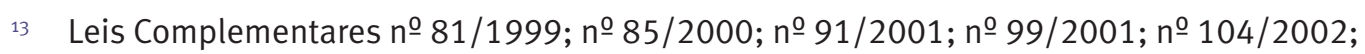

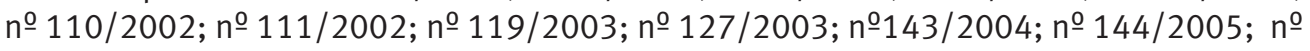
$146 / 2005 ;$ no 156/2006 e no 199/2009.

14 Referente ao valor do salário mínimo em 2010. 
inicial de $R \$ 1.675,79$ equivale a 3,6 salários mínimos, sem considerar que também houve um aumento real no valor do salário mínimo, nesses últimos anos. Em relação aos demais estados brasileiros, o Acre registra, hoje, um dos melhores salários de professores do País.

Almeida Júnior (2006) explica que a política de valorização salarial contribuiu para consolidar um estilo de governança com controle e negociação e também para fortalecer a capacidade institucional necessária para a realização de mudanças no quadro de reformas educacionais. Assim, com a valorização salarial da categoria profissional docente, a questão da remuneração saiu do foco do debate, centrando-se na qualidade da educação e na responsabilização dos sujeitos - diretores e professores - para sua consecução.

\section{A POLÍTICA DE FORMAÇÃO DOS PROFESSORES}

Os desafios colocados pela realidade de ensino no Acre levaram a Secretaria de Educação a implantar um sistema de formação de profissionais da educação que somava mais de quarenta projetos voltados tanto para a formação dos professores leigos, quanto para a formação inicial e continuada dos professores que tinham apenas o magistério em nível médio.

Um dos graves problemas do Acre no campo da formação docente era 0 número de professores leigos, que chegava a 19\%, segundo dados do Instituto Nacional de Estudos e Pesquisas Educacionais (INEP, 1999). Esses professores possuíam apenas o ensino fundamental completo ou incompleto; não tinham, portanto, nem a formação mínima exigida para exercer o magistério. Até o ano 2000, esses dados pouco sofreram alterações. É nesse ano que tem início uma ampla política de formação de professores.

Inicialmente, foi implantando o Programa de Formação de Professores em Exercício (Proformação) resultante da demanda do Fundo de Manutenção e Desenvolvimento do Ensino Fundamental e de Valorização do Magistério (FUNDEF), criado em 1996 pela Emenda Constitucional no 14 e regulamentado pela pela Lei no 9.424/96 que, em seu artigo 7ํㅜ, parágrafo único, estabelecia que, nos primeiros cinco anos, a contar de sua publicação, parte dos recursos da parcela de $60 \%$ destinada à remuneração dos profissionais do magistério deveria ser usada para capacitação de professores leigos. Esse curso teve uma duração de dois anos, iniciando-se em 2000 e encerrando-se no final de 2001.

O Proformação foi desenvolvido pelo Ministério da Educação e oferecia um curso de magistério em nível de ensino médio aos professores leigos 
em exercício. Segundo Placco, André, e Gatti (2003), esses professores, por intermédio desse curso, conseguiram se inserir em um processo de profissionalização mais bem construído. Para isso, foram determinantes: (a) a organização do currículo, em que as práticas pedagógicas foram tomadas como eixo articulador de todo o processo de aprendizagem; (b) a boa qualidade dos materiais de suporte; (c) o acompanhamento contínuo dos tutores e (d) o contato com os professores formadores.

No Acre, alguns fatores dificultaram esse processo de formação, em função do desenho do Programa. Um exemplo disso foi o nível de formação dos tutores, visto que aqueles que possuíam nível superior não queriam se deslocar para atender os professores cursistas nas localidades mais distantes em meio à floresta. O deslocamento desses professores cursistas nos períodos de formação presencial também foi outra dificuldade, devido à distância de seus locais de residência e trabalho. A maioria desses professores leigos trabalhava em escolas rurais e em localidades de difícil acesso, algumas delas próximas à fronteira com o Peru. Mesmo com esses problemas que dificultaram o desenvolvimento do Programa, segundo os dados da própria Secretaria de Estado de Educação do Acre, o índice de aprovação foi de 89,2\% no Estado, qualificando 1.634 professores em nível médio em um total de 1.844 , reduzindo drasticamente o índice de professores leigos.

Outro problema presente no quadro educacional do Estado era a ausência de professores com nível superior. Esse dado foi considerado pelo governo como o fator principal do desempenho insatisfatório dos alunos nas avaliações do Sistema de Avaliação da Educação Básica (Saeb) e da dificuldade da universalização dos anos finais do ensino fundamental e do ensino médio, pois não se tinha no Estado, no início dos anos 2000, um número suficiente de professores com formação adequada para atuar nessas etapas da educação básica. Diante desse fato, o governo acabou por firmar convênio com a Universidade Federal do Acre e implementou vários programas de formação inicial de professores para a educação básica. A primeira fase desse projeto ocorreu entre 2000 e 2004, com o Programa Especial de Formação de Professores para a Educação Básica (PEFPEB) e foi destinado aos professores em efetivo exercício da docência, sendo sua clientela selecionada entre os professores das redes públicas estadual e municipais. À exceção da Capital, nos demais municípios foram abertas vagas para candidatos da comunidade que não eram docentes da rede, iniciativa que promoveu a interiorização da educação superior no Acre. 
Os cursos foram realizados em nove municípios acrianos, num total de 37 turmas, distribuídas entre os municípios de Rio Branco, Tarauacá, Feijó, Sena Madureira, Brasiléia, Plácido de Castro, Senador Guiomard, Xapuri e Cruzeiro do Sul. O Programa abrangeu seis cursos em regime modular nas áreas de Matemática, Geografia, Educação Física, História, Letras e Biologia e qualificou 1.526 professores que atuavam nas escolas públicas de educação básica, conforme os dados da Secretaria de Educação.

A segunda fase desse Programa teve início em 2001, com a implementação do Programa Especial de Formação de Professores para a Educação Básica Educação Infantil e Séries Iniciais do Ensino Fundamental - licenciatura Plena em Pedagogia que se encerrou em 2004. Esse projeto foi implementado em todo o Estado, mediante a criação de pólos formadores com o objetivo de qualificar em nível superior mais de 2.800 professores que atuavam na educação infantil e anos iniciais do ensino fundamental das escolas das redes estadual e municipais.

Nesses processos de formação, foram atendidos, prioritariamente, os professores que trabalhavam no meio urbano, tanto na capital quanto nos municípios. Enquanto isso, os professores que tinham concluído o Proformação, desde o final de 2001, ainda esperavam por uma oportunidade de cursarem uma graduação. Tal oportunidade surgiu com o Programa Especial de Formação de Professores para a Educação Básica da Zona Rural, que atende, atualmente, 2.389 professores nas seguintes Licenciaturas: Letras/ Português, Ciências Biológicas, Matemática, História, Geografia, Educação Física e Pedagogia. Os cursos desse Programa têm duração de cinco anos, tendo iniciado em 2007, com a previsão de término em 2011.

Também foi estendido, em 2006, aos professores que trabalham em localidades de difícil acesso, ${ }^{15}$ o Programa Especial de Formação de Professores para a Educação Básica, atendendo um total de 720 professores, em seis municípios. Oferta cursos de licenciatura em Letras/Português, Ciências Biológicas e Matemática.

Em 2007, a Universidade Aberta do Brasil (UAB) começou a atuar no Estado com os cursos de licenciatura em Pedagogia e Artes (Visuais, Teatro e Música), na modalidade a distância. Esses cursos são oferecidos pela Faculdade de Educação da Universidade de Brasília, atendendo cerca de 1.700 professores da rede pública de ensino municipais e estadual. Os cursos são ministrados

15 Trata-se de municípios que não tem acesso por malha rodoviária asfaltada. 
nos pólos dos municípios de Rio Branco, Tarauacá, Brasiléia, Sena Madureira e Cruzeiro do Sul.

A política de formação de professores desenvolvida nessa última década possibilitou um avanço significativo no número de professores da área urbana com formação em nível superior que, segundo dados da própria Secretaria de Educação, passou de 28\% em 1999, para mais de $90 \%$, atualmente. A projeção da Secretaria de Estado de Educação é ter 100\% de seus professores de meios rural e urbano com formação de nível superior até o final do ano de $2011 .{ }^{16}$

Além da política de formação inicial de professores, a formação continuada também se constituiu em ação efetiva, no movimento de reformas educacionais da primeira gestão da Frente Popular do Acre. Entre 1999 e 2002, os programas de formação continuada envolveram um grande volume de projetos em cooperação com o MEC voltados para uma demanda comum - a melhoria da qualidade de educação. Podem-se citar alguns deles, como: os Parâmetros Curriculares em Ação, Programa de Formação para Professor Alfabetizador (PROFA), Programa de Formação Continuada em Gestão Escolar (PROGESTÃO), Programa de Aceleração de Aprendizagem, Programa de Aprendizagem Escolar (GESTAR), Programa Escola Ativa, etc. ${ }^{17}$

Considerando todas as políticas educacionais do processo de reforma educacional do Acre, desde 1999, no tocante à formação de professores em serviço, pode-se afirmar que, atualmente, o estado não apresenta mais nenhuma demanda ao governo federal. Prova disso é que, diante do Plano Nacional de Formação de Professores da Educação Básica do Ministério da Educação, em colaboração com as secretarias de educação dos estados e municípios e as instituições públicas de educação superior, das 27 unidades da Federação, além do Distrito Federal, o Acre não apresentou demandas em relação a essa política.

Pode-se perceber que as políticas públicas de formação de professores foram consideradas uma questão chave no processo de reformas frente aos desafios colocados pela realidade de ensino do Acre, obtendo um significativo avanço nesse campo. No entanto, essa política no âmbito do projeto de reforma educacional assumiu, ao longo do período aqui analisado (1999-2009), duas orientações.

16 Cf. Agência de Notícias do Acre, 07/01/2009.

17 Todos os programas citados são de iniciativa do Ministério da Educação (MEC) com adesão do Governo do Estado do Acre, em regime de colaboração. 
A primeira delas, inicialmente adotada, está sintonizada com a orientação defendida pelos grupos de educadores cujo pensamento filia-se às idéias defendidas pelas associações docentes, ao escolher a Universidade Federal do Acre como a instituição responsável pelo processo formativo dos professores das redes estadual e municipal, ao adotar um modelo de formação presencial, com carga horária significativa, com mais de 3.000 horas distribuídas entre créditos teóricos, práticos e de estágio.

Foi outra a orientação política dos últimos anos, referente à formação de professores em nível superior. Essa formação adotou a modalidade de curso a distância, com a oferta de cursos de licenciatura em Pedagogia, Teatro, Artes Visuais e Música, em parceria com a Universidade de Brasília (UnB), por meio da Universidade Aberta do Brasil (UAB). Esse modelo de formação de professores a distância é coerente com as recomendações estabelecidas pelos organismos internacionais, principalmente pelo Banco Mundial, que privilegia essa modalidade para a formação inicial de professores em exercício, por conjugar custos mais baixos com uma concepção instrumental do trabalho docente. Segundo Santos (2011, p.3):

\begin{abstract}
Esses cursos se diferenciam completamente dos cursos regulares e presenciais, nos quais o estudante tem oportunidade de vivências que não se restringem às atividades de sala de aula, o que amplia seus horizontes e sua formação profissional. Acrescenta-se a isso o fato de esses cursos reforçarem o individualismo tão presente hoje na sociedade de consumo, uma vez que as atividades presenciais são muito limitadas. Os alunos de um curso presencial têm oportunidade de trabalhar em grupo, de se confrontar com pessoas que pensam diferente deles. Sobretudo, por meio de diretórios acadêmicos e grêmios acadêmicos, podem se engajar em atividades políticas e sociais, desenvolvendo o espírito de solidariedade e de reivindicação, além de terem maior possibilidade de participar de atividades culturais desenvolvidas nas instituições em que estudam.
\end{abstract}

Há que se reconhecer, entretanto, que a oferta de cursos e programas de educação superior a distância por instituições públicas de ensino superior, como a UnB, em articulação com pólos de apoio presencial, nos municípios, representa, sem dúvida, um avanço em relação aos programas de formação a distância, de curta duração, de caráter mercadológico, que são oferecidos por várias instituições privadas. No entanto, em um campo tão importante, como o da formação inicial, não há dúvida de que a educação a distância, mesmo de boa qualidade, não consegue se igualar a uma boa formação inicial presencial.

Como pode ser observado, também no caso das políticas voltadas para a formação de professores em nível superior, há uma mescla de diferentes 
concepções de formação. Apesar de seguir orientações diferentes, podese constatar que o resultado dessas políticas foi positivo, uma vez que não se pode deixar de reconhecer a inclusão cultural, social e econômica dos professores da rede de ensino, permitindo uma melhor qualidade de vida, proporcionada por um maior nível de escolarização e, consequentemente, por um melhor salário.

\section{CONCLUSÃO}

Contrariamente aos modelos de reforma de orientação mais econômica, nos quais se reduz o papel do Estado, no Acre, esse papel foi ampliado, com um considerável aumento de gastos públicos com a educação. O volume de recursos investidos, nessa última década, em construção, reforma e ampliação de escolas da rede estadual, e principalmente, em programas de formação de professores, foi superior aos dos governos anteriores. Para se ter uma idéia desse volume de recursos, só nos primeiros quatro anos de reforma educacional, o governo Jorge Viana aumentou em $61 \%$ a média anual de recursos aplicados em educação e cultura, em relação à média de recursos do governo anterior, no período de 1995 a $1998 .{ }^{18}$ Nos últimos dez anos, foram implantadas 827 obras de educação no Acre, com investimentos diretos de mais de $\mathrm{R} \$ 190$ milhões. Desse total, 226 escolas foram construídas, reformadas ou ampliadas gestão de Arnóbio Marques. Os investimentos com as políticas de formação superior dos professores da rede pública de ensino somaram quase $\mathrm{R} \$ 50$ milhões, desde 1999, e os gastos com a folha de pagamento da educação saltaram de $\mathrm{R} \$ 5$ milhões, em 1999, para mais de R\$ 32 milhões em 2010, sendo que $80 \%$ dos recursos da educação são destinados à remuneração (Cf. Informações da Assessoria da SEE/AC, em 29/10/2010). Com isso, o estado não desapareceu e nem privatizou os bens públicos. A educação recebeu grande atenção do governo, considerando seu papel político, como instrumento de equidade social.

Constata-se que algumas medidas tomadas nas reformas na área da educação, principalmente no que diz respeito à gestão das escolas, estão muito centradas na definição de metas e na avaliação do desempenho, que são procedimentos muito utilizados pelo "novo gerencialismo". No entanto, a simples utilização desses procedimentos não define a orientação de uma política pública, pois é preciso conhecer melhor suas finalidades e

\footnotetext{
A média anual de recursos aplicados em educação e cultura pelo governo Orleir Cameli foi de $R \$ 115.407 .500,00$ (cento e quinze milhões, quatrocentos e sete mil e quinhentos reais); já no governo Jorge Viana, a média foi de 185.775.201 (cento e oitenta e cinco milhões, setecentos e setenta e cinco mil e duzentos e um reais).
} 
seu conteúdo. Da mesma forma, a qualificação dos professores é medida necessária, mas não suficiente para a melhoria da qualidade da educação, pois é preciso também avaliar a qualidade dos cursos oferecidos. Do mesmo modo, equipar as escolas é um aspecto importante, mas é também necessário investigar como os novos equipamentos estão sendo utilizados. É difícil precisar os efeitos das políticas públicas, principalmente, porque muitos deles só podem ser avaliados em longo prazo.

0 uso do termo hibridismo na contemporaneidade tem como objetivo mostrar que não é possível se pensar em posições puras e em determinações unívocas. Segundo Dussel (2002, p. 65), "a hibridação não só se refere a combinações particulares de questões díspares, como nos recorda que não há formas (...) puras nem intrinsecamente coerentes, ainda que essa mescla não seja intencional”. Assim, não é possível analisar a política de reformas educacionais do Acre dentro de modelos que buscam enquadrálas como parte da um projeto totalmente afinado com as teorias críticas no campo educacional ou de um projeto orquestrado por princípios neoliberais. Não se pode dizer que as reformas educacionais no estado do Acre foram dirigidas somente pelo ideário dos educadores considerados progressistas, ou dirigidas sobretudo por princípios econômicos, em que as ações são propostas considerando apenas as taxas de retorno do investimento ou sua importância para o mercado de trabalho, por exemplo. Não se pode dizer tampouco que o aumento do controle em diferentes níveis faça parte das propostas consideradas gerencialistas. As reformas do Acre mesclam diferentes matrizes políticas e se constroem como algo diferenciado e singular. Nesse sentido o termo híbrido rompe com a idéia de determinações unívocas, pois, esse novo híbrido é, ao mesmo tempo, resultado de uma ruptura e de uma associação de orientações e concepções que se assentam em diferentes perspectivas teóricas, políticas e práticas.

O caráter híbrido na definição dessas políticas educativas remete para 0 entendimento de que a importação de modelos legitimados por agências internacionais ou até mesmo os modelos de políticas advindas de alguns estados brasileiros mais ricos e de maior desenvolvimento educacional são modificados no confronto com o contexto local, ou seja, modelos vindos de fora se mesclam com a realidade acriana, deixando de ser meras transposições de outras realidades, adquirindo características próprias. Apesar, porém, de todos os aspectos positivos presentes nas políticas educacionais do Acre, vale ressaltar uma preocupação com os rumos futuros das propostas educacionais, não só adotadas pelo Acre, mas por todos os entes federados, 
uma vez que a ênfase dessas políticas está muito mais circunscrita aos resultados de aprendizagem de determinados conhecimentos e capacidades intelectuais, sem uma preocupação maior com uma importante dimensão: as pessoas que estão sendo escolarizadas serão realmente capazes de construir um mundo melhor e mais justo do que este em que vivemos?

Somente uma análise de mais longo prazo ou mesmo uma análise mais abrangente que situe essas políticas no contexto das demais políticas públicas, das tradições e da história das políticas públicas do Acre poderá avaliá-las de maneira mais ampla e refinada. O princípio de justiça social deverá ser o critério a partir do qual os resultados dessas políticas poderão ser analisados de forma mais completa e rigorosa. Ao invés das análises se centrarem apenas na origem dessas políticas, é preciso, principalmente, identificar seus efeitos.

Este artigo focalizou apenas os resultados mais evidentes dessas políticas, em termos de melhorias na educação. Um quadro mais completo será dado à medida que se acumulem trabalhos sobre esse tema. Investigações em que se examinem com mais acuidade as conseqüências dessas políticas e em que as melhorias no campo educacional sejam analisadas de forma mais profunda; estudos em que se considerem não apenas resultados em testes, mas também as atitudes, valores e o comportamento social dos alunos na análise de seu desempenho escolar; pesquisas que não estejam centradas apenas nas estatísticas sobre formação docente, mas também no compromisso dos professores com a educação e com a qualidade de seu trabalho; estudos que não se refiram somente às condições da infra-estrutura e de equipamentos disponíveis, mas também às condições de trabalho da escola e a sua dinâmica interna: os resultados dessas pesquisas poderão, sem dúvida, auxiliar a compor um quadro mais complexo dos efeitos de políticas educacionais. 


\section{Educational reform in Acre: A hybrid model}

\section{ABSTRACT}

This paper looks at educational reform proposals that were adopted in the state of Acre, in the period between 1999 and 2009. It argues that these proposals took on a hybrid nature, in which there is a mix of two different guidelines: those of a more economic nature, fine-tuned using the principles and practices of new generationalism, and those of a more progressive nature, which are coherent with critical theories and in which education is seen as a form of social emancipation. To do this, policies were analyzed that dealt with training, careers and salaries for public school teachers in the state system, in an effort to learn about the different rationales, discourses, and political actions implemented in the reform movement in order to show their social dynamic. The conclusion is reached that under this hybrid model, the results of the reforms analyzed have proven to be quite positive and it is suggested that a more complete balance of these policies may only be achieved in the long term, through new investigations where the issue of social justice is considered as a criterion. Finally, this kind of study is seen as something that can only be done in a context where analysis is based not only on statistical data, but also on aspects that consider the educational process as a process of human formation.

\section{KEYWORDS}

Educational Reform. Educational policy. Teaching Work. Education in Acre. 


\section{Referências}

ACRE. Lei Complementar № 63, de 13 de Janeiro de 1999. Dispõe sobre a reorganização da Administração Pública e dá outras providências. Assembleia Legislativa do Estado do Acre. Rio Branco, 1999. Disponível em: 〈http. www. aleac.ac.gov.br>. Acesso em 03/10/2011.

ACRE. Lel Complementar № 67, de 29 de junho de 1999. Dispõe sobre o Plano de Cargos, Carreira e Remuneração dos Profissionais do Ensino Público Estadual e dá outras providências. Assembléia Legislativa do Estado do Acre. Rio Branco, 1999. Disponível em: 〈HTTP: www.aleac.ac.gov.br〉. Acesso em: 03 fev. 2009.

ACRE. LeI Complementar № 72, de 05 de julho de 1999. Dispõe sobre a organização das secretarias de governo. Assembleia Legislativa do Estado do Acre. Rio Branco, 1999. Disponível em: 〈http. www.aleac.ac.gov.br〉. Acesso em 03/10/2011.

ACRE. LeI COMPLEMENTAR No 81, de 29 de dezembro de 1999. Dá nova redação ao art. 60 da Lei Complementar n. 67, de 29 de junho de 1999. Assembléia Legislativa do Estado do Acre. Rio

ACRE. LeI COMPLEMENTAR No․ 85, de 3 de julho de 2000. Altera o parágrafo único do art. 84 da Lei Complementar n. 63, de 13 de janeiro de 1999. Assembléia Legislativa do Estado do Acre. Rio Branco, [2000]. Disponível em: 〈http. www. aleac.ac.gov.br/>. Acesso em: 5 mar. 2009.

ACRE. LeI COMPLEMENTAR №. 91, de 14 de fevereiro de 2001. Altera e acresce dispositivos à Lei Complementar n. 67, de 29 de junho de 1999 e dá outras providências. Assembléia Legislativa do Estado do Acre. Rio Branco, [2001]. Disponível em: 〈http. www.aleac.ac.gov.br/〉. Acesso em: 5 mar. 2009.

ACRE. Lel Complementar №. 99, de 17 de dezembro de 2001. Acresce dispositivos às Leis Complementares ns. 84, de 28 de fevereiro de 2000 e 67, de 29 de junho de 1999 e às Leis ns. 1.384, de 24 de maio de 2001; 1.413, de 19 de setembro de 2001; 1.416, de 24 de outubro de 2001; 1.417 ; de 24 de outubro de $2001 ; 1.418$, de 24 de outubro de 2001 e 1.419 , de 1 으 de novembro de 2001 e dá outras providências. Assembléia Legislativa do Estado do Acre. Rio Branco, [2001]. Disponível em: 〈http. www.aleac.ac.gov. br>. Acesso em: 5 mar. 2009. 
ACRE. LeI COMPLEMENTAR No․ 104, de 4 de janeiro de 2002. Acresce e altera dispositivos da Lei Complementar n. 67, de 29 de junho de 1999. Assembléia Legislativa do Estado do Acre. Rio Branco, [2002]. Disponível em: 〈http. www. aleac.ac.gov.br/M001/>. Acesso em: 5 mar. 2009.

ACRE. LeI Complementar №. 110, de 28 de junho de 2002. Altera a Lei Complementar n. 67, de 29 de junho de 1999, que Dispõe sobre o Plano de Cargos, Carreira e Remuneração dos Profissionais do Ensino Público Estadual. Assembléia Legislativa do Estado do Acre. Rio Branco, [2002]. Disponível em: 〈http. www.aleac.ac.gov.br〉. Acesso em: 5 mar. 2008.

ACRE. LeI Complementar No․ 111, de 04 de julho de 2002. Altera a Lei Complementar n. 67, de 29 de junho de 1999, que “Dispõe sobre o Plano de Cargos, Carreira e remuneração dos Profissionais do Ensino Público Estadual. Assembléia Legislativa do Estado do Acre. Rio Branco, [2002]. Disponível em: 〈http. www.aleac.ac.gov.br〉. Acesso em: 8 mar. 2009.

ACRE. LeI COMPLEMENTAR No․ 119, 09 de julho de 2003. Altera dispositivos da Lei Complementar n. 67, de 29 de junho de 1999. Assembléia Legislativa do Estado do Acre. Rio Branco, [2003]. Disponível em: 〈http. www.aleac.ac.gov. br>. Acesso em: 8 mar. 2009.

ACRE. LeI COMplementar №. 127, de 29 de dezembro de 2003. Altera a Lei Complementar no 67, de 29 de junho de 1999, que dispõe sobre o Plano de Cargos, Carreira e Remuneração dos Profissionais do Ensino Público Estadual. Assembléia Legislativa do Estado do Acre. Rio Branco, [2003]. Disponível em: 〈http. www.aleac.ac.gov.br〉. Acesso em: 8 mar. 2009.

ACRE. Lei Complementar №. 143, de 27 de dezembro de 2004. Altera dispositivos da Lei Complementar n. 67, de 29 de junho de 1999. Assembléia Legislativa do Estado do Acre. Rio Branco, [2004]. Disponível em: 〈http. www. aleac.ac.gov.br.. Acesso em: 8 mar. 2009.

ACRE. LeI Complementar No․ 144, de 4 de março de 2005. Institui a nova estrutura de vencimentos dos profissionais do ensino público estadual e altera dispositivos da Lei Complementar n. 67, de 29 de junho de 1999. Assembléia Legislativa do Estado do Acre. Rio Branco, [2005]. Disponível em: 〈http. www.aleac.ac.gov.br〉. Acesso em: 8 mar. 2009.

ACRE. LeI COMPLEMENTAR No. 156, de 26 de janeiro de 2006. Revoga dispositivos das Leis Complementares n. 67, de 29 de junho de 1999 e 144, de 4 de março de 2005. Assembléia Legislativa do Estado do Acre. Rio Branco, [2006]. 
Disponível em: 〈http. www.aleac.ac.gov.br〉. Acesso em: 8 mar. 2009.

ACRE. LeI Complementar $N^{0}$ 191, de 31 de dezembro de 2008. Dispõe sobre a estrutura administrativa do Poder Executivo do Estado do Acre e dá outras providências. Assembleia Legislativa do Estado do Acre. Rio Branco. Disponível em: 〈http. www.aleac.ac.gov.br〉. Acesso em: 03/10/2011.

ACRE. Lei COMPLementar Noํ. 199, de 23 de julho de 2009. Altera as Leis ns. 1.384 , de 24 de maio de 2001; 1.394 , de 28 de junho de $2001 ; 1.704$, de 26 de janeiro de 2006; 1.907, de 24 de julho de 2007; 1.956 , de 4 de dezembro de 2007, e as Leis Complementares ns. 67, de 29 de junho de 1999; 84, de 28 de fevereiro de 2000; 102, de 26 de dezembro de 2001 e 167, de 24 de julho de 2007. Assembléia Legislativa do Estado do Acre. Rio Branco, [2009]. Disponível em: 〈http. www.aleac.ac.gov.br〉. Acesso em: 14 abri 2009.

ACRE. LEI $N^{0} 1.513$, de 11 de novembro de 2003. Dispõe sobre a gestão democrática do sistema de ensino público do Estado do Acre e dá outras providências. Assembléia Legislativa do Estado do Acre. Rio Branco, 2003. Disponível em: 〈http. www.aleac.ac.gov.br〉. Acesso em 10/10/2007.

ALMEIDA JÚNIOR, Arnóbio Marques. O PLANEJAMENTo ESTRATÉgICO E A REFORMA EDUCACIONAL DO ACRE, 2006. Dissertação (Mestrado em Educação). Rio de Janeiro: Universidade Federal do Rio de Janeiro: Faculdade de Educação, 2006. $145 \mathrm{f}$.

BALL, Stephen. ETAL. REFORMING EDUCATION \& CHANGING SCHOOLS: case studies in policy sociology. Londres: Routledge, 1992.

BALL, Stephen. EDUCATIONAL REFORM - a critical and post-structural approach. Buckingham; Philadelphia: Open University Press, 1994.

BARACHO, Ernani; FERREIRA, Edmilson. Notícias Educação: Governo abre concurso para contratação de 800 professores efetivos. AGÊNCIA DE NOTÍCIAS DO ACRE ON LINE, Rio Branco, 08 de outubro de 2010. Disponível em:ıhttp://www. ac.gov.br/wps/wcm/connect/agencia+noticias/portal+agencia+de+noticias/ noticias/educacao/d276b8804b8ce60b0c6f3c6033aad24> Acesso em: 23.10.2010.

BELCHIOR, M. A aPLICAÇÃo de PLANEJAMENTO ESTRATÉGICO SITUACIONAL EM GOVERNOS LOCAIS: possibilidades e limites: 1999. Dissertação (Mestrado em Administração). São Paulo: Fundação Getúlio Vargas, Escola de Administração de Empresas de São Paulo (EAESP), 1999. 
BRASIL. LEI No 9.424, de 24 de dezembro de 1996. Dispõe sobre o Fundo de Manutenção e Desenvolvimento do Ensino Fundamental e de Valorização do Magistério - FUNDEF. Diário Oficial da União, Brasília, DF, 26 dez. 1996.

DUSSEL, I. O currículo híbrido: domesticação ou pluralização das diferenças? In: LOPES, A.R.C. e MACEDO, E. (org.). CURRÍCULO: debates contemporâneos. São Paulo: Cortez, 2002, p.137-168.

FERREIRA, Edmilson. Governo e Ufac iniciam quarta etapa do programa de formação de professoresrurais.JORNALAGÊNCIADENOTÍCIASDOACREON LINE, Rio Branco, 07 de janeiro de 2009. Disponível em: 〈http://www.agencia.ac.gov. br > Acesso em: 19 maio 2009.

FONSECA, Marília. Projeto político pedagógico e o Plano de Desenvolvimento da Escola: duas concepções antagônicas de gestão escolar. CAD. CEDES, Campinas, v. 23, n. 61, p. 302-318, dez. 2003.

GARCÍA CANCLINI, Néstor. CULTURAS HÍBRIDAS: estratégias para entrar e sair da modernidade. São Paulo: Edusp, 2008.

IBGE. Instituto Brasileiro de Geografia e Estatística. Sinopse do Censo Demográfico 2010. Rio de Janeiro, 2010.

INEP. Instituto Nacional de Estudos e Pesquisas Educacionais. Censo Escolar da Educação Básica: 2009. Brasília: INEP, 2010.

INEP. Instituto Nacional de Estudos e Pesquisas Educacionais. Censo do professor 1997: perfil dos docentes de Educação Básica. Brasília, DF: INEP, 1999.

MATUS, Carlos. AdIOS, SEÑOR PRESIDENTE: governantes governados. 3. ed. Caracas: Altadir, 1994.

MATUS, Carlos. Política, Planejamento e Governo. Brasília: IPEA, 1993.

PLACCO, V. M. N.S; ANDRÉ, M. E. D. A; GATTI, B. A. Proformação: Avaliação Externa. Brasília: MEC/SEED - Secretaria de Educação a Distância, 2003.

SANTOS, Lucíola L. de C. P. Identidade docente em tempos de educação inclusiva. In: VEIGA, Ilma P. A.; AMARAL, Ana Lúcia. (org.). ForMAÇÃO DE PROFESSORES: políticas e debates. 2. ed. Campinas, São Paulo: Papirus, 2003. 
SANTOS, Lucíola L. Formação docente: questões atuais. In: DALBEN, A. I. L. F e COSTA, T.M.L. (Org.). NúCLEO DE INTEG RAÇÃO. Belo Horizonte: UFMG/FAE, 2011, p. 9-32.

SANTOS, Lucíola L. Tensões no campo da formação inicial de professores. In: XI CONGRESSO DA SOCIEDADE PORTUGUESA DE CIÊNCIAS DA EDUCAÇÃO. Guarda, 2 de junho de 2011.

SANTOS, Lucíola L. de C. P.. Educação Inclusiva: Desafios e Impasses. In: XXIV SIMPÓSIO BRASILEIRO DE POLÍTICA EAdMINISTRAÇÃO DAEDUCAÇÃO/IIICONGRESSO INTERAMERICANODEPOLÍTICAEADMINISTRAÇÃOdAEDUCAÇÃO, 2009, EspíritoSanto. Anais. Espírito Santo: ANPAE/UFES, 2009. p. 1-15.

Recebido em: OUTUBRO de 2011

Aprovado em: NOVEMBRO de 2011 